\title{
Negotiating social meanings in a plural society: social perceptions of variants of /1/in Singapore English
}

\section{Jasper Hong Sim ${ }^{1}$}

University of Cambridge

This study illustrates how differential speech features that emerged from language contact and acquisition in a linguistically and culturally pluralistic society can accrue diverse social-indexical meanings over time. The social perceptions towards three variants of coda / $/$ in Singapore English, namely dark-l, the variant associated with prescriptive norms, and clear-l and vocalised-l, which are variants that arose through language contact, were examined. The findings revealed that the meanings of the local variants are equally diverse, but have evolved differently; vocalised-I is an emerging local standard, whereas clear-l remained largely stigmatised. The diverse meanings are also shown to be connected by social factors within a larger network of interrelated signs, and that their interpretations are dependent on the hearer's experiences, such that we are observing different parts of the sociolinguistic reality. Restricted experiences with the social world and regulation of social perception were also shown to potentially contribute to accent-based prejudices.

Keywords: indexicality; language contact; ethnolect; laterals; new Englishes; social perception

\footnotetext{
${ }^{1}$ Email: Jhs71@cam.ac.uk
} 


\section{Introduction}

Differential speech features that emerge from language contact and acquisition, such as those that characterise British Asian English (e.g. Kirkham, 2017; Sharma, 2011) or structural innovations in New English varieties (e.g. Deterding, 2007a; Gut, 2011) can come to gain social-indexical meanings. These features can become emblematic of a particular socio-demographic group or context based on association by contiguity (Agha, 2007; Silverstein, 2003), and can be selectively used in the creative construction of social personae, styles and identities, such as through the adoption of a more ethnic repertoire (Benor, 2010). Like other indices, social meanings of differential features are mutable along with the constantly evolving social landscape, where they are (re-)interpreted as they are used (Eckert, 2012), and may become reallocated with new social functions across generations (e.g. Gnevsheva, 2020; Sharma \& Sankaran, 2011). This is the case for multilinguistic communities who have experienced or are experiencing shifts in language use at the societal level, in which social meanings may constantly emerge and evolve, along with what is considered as standard/mainstream or local/marked. Moreover, in culturally and linguistically pluralistic societies, the interpretation of a feature can vary between individuals; not only can one feature index several distinct social personae and qualities, but there is also considerable variation in the backgrounds of the listeners and their experiences with the sociolinguistic world (Johnstone \& Kiesling, 2008). This study examines the social perceptions towards three variants of coda / / in Singapore English ( $\mathrm{SgE}$ ): dark-l, the variant associated with prescriptive norms, and clear-l and vocalised-l, which are variants that arose through language contact. The key findings revealed that while the local variants are primarily associated with the ethnic groups whose other language(s) may have contributed to their emergence, their meanings may have evolved differently; vocalised-l is perceived by many to be pan-Singaporean and is ascribed social meanings of dark-l that suggest an emerging local standard, whereas clear-l remains exclusively associated with the ethnic minorities and is largely stigmatised. The three variants are also revealed to have very diverse and sometimes conflicting social meanings. These are described to be interrelated in a highly complex meaning network and linked by various social factors, and the myriad interpretations are but fragments of a whole sociolinguistic reality, and shaped by their experiences with the complex sociolinguistic reality or a lack thereof. Drawing on Eckert's (2008) notion of an indexical field, the social-indexical meanings of these variants are further organised in a shared space, which is shown to potentially be a means to document change in meanings in response to the evolving sociolinguistic landscape. 


\subsection{Social-indexical meanings of $/ l$}

The way differential features become recognised as characteristic of a dialect (e.g. Schneider, 2012) or associated with a particular ethnic/cultural affiliation (Benor, 2010; Eckert, 2008b; Hoffman \& Walker, 2010) is enabled through a sociohistorical process of what Agha (2007) termed 'enregisterment', which refers to "processes and practices whereby performable signs become recognised (and regrouped) as belonging to distinct, differentially valorised semiotic registers by a population" (p. 81). Many studies have shown that a single variable can carry social meanings, and manipulating a single phone is enough to alter the hearer's evaluation of a speaker (e.g. Chappell, 2016; Plichta \& Preston, 2005; Walker, García, Cortés, \& Campbell-Kibler, 2014). According to Silverstein (2003), such indexical associations can occur at different levels of abstraction or 'orders of indexicality'; a linguistic form gains higher-order indexicality when it gains new meanings that presuppose lower-order meanings. These multiple related social meanings can be further organised in what Eckert (2008, p.467) described as an indexical field "a constellation of meanings that are ideologically linked." Using hyperarticulated $/ \mathrm{t} /$ release as an example, she showed how the feature is associated with clarity and emphasis in American English, and in turn their ideological associations allow speakers to employ $/ t /$ release to index different social types, such as nerd girls and gay divas. In other words, the same variant might index different semantically related qualities depending on the context; it may, for instance, index educatedness and nerdiness when used by nerd girls, but prissiness when used by gay divas.

Previous work has shown how allophones of the alveolar lateral can be used in socially meaningful ways. Cross-linguistically, alveolar laterals differ with regard to their degree of velarisation and/or pharyngealisation, with some languages having a darker (more velarised or pharyngealised) variant than others (Recasens, 2012). In addition, some languages exhibit a clear or dark variant in all syllable positions, while in others they are syllabically conditioned (Recasens, 2004; Recasens \& Espinosa, 2005). Varieties of Southern British English, for example, are often described to have clearer $/ 1 /$ in the onset and a darker /l/ in the coda (Wells, 1992).

Contrastingly, likely due to effects of cross-linguistic influence of languages with clearer /l/ variants such as Panjabi, Urdu and Arabic, British Asian English is often characterised as having clearer allophones of coda /1/ (e.g. Khattab, 2002; Kirkham, 2017; Sharma, 2011). In her study of second generation British Asians, Sharma (2011) found that some speakers constructed different personae by being more ethnic in their speech features towards family members and India-born speakers, but more mainstream with Anglo speakers. Differential features can also emerge from and evoke attitudes that are linked with various socio-historical and -political processes. One such example is Simonet's (2010a) study of the alveolar laterals of Catalan-Spanish bilinguals. Majorcan Catalan has dark-l in all positions, while Spanish has clear-l in all positions. Simonet (2010a, 2010b) found that, particularly in Majorca, not only is darker /l/ associated with 
Catalan-dominant Catalan-Spanish speakers, but it also indexes local and perhaps rural origins of the speaker. Simonet explained that this was perhaps so because Spanish monolingual speakers settled mostly in the main Majorcan metropolitan areas during the mass migratory waves in the 1950s and 1960s, when Majorcan Catalan had a low level of social prestige for socio-political reasons. This led Simonet to argue that a reason why his Spanish-dominant female subjects had a merged $\mathrm{L} 1+\mathrm{L} 2$ lateral category could be because they may have distanced themselves from what they might have perceived as Catalan-accented Spanish, which could also explain why they also produced clearer laterals than older females of similar linguistic background.

\subsection{Variants of coda $/ / /$ in Singapore English}

Many structural innovations in New English varieties can attributed to various influences of the indigenous languages/substrates (Gut, 2011; Schneider, 2003). Similar to the formation and use of ethnolects (e.g. Gnevsheva, 2020; Sharma \& Sankaran, 2011), these features can stabilise to form a widely accepted local variety, as is the case of Singapore English (Deterding, 2007a), and are adopted by later generations of speakers and remain in production even if speakers have attained proficiency in English, and further be reallocated with social meanings. Therefore what would have been learner errors or effects of cross-linguistic influence for one generation may be acquired from the input by later generations of speakers, and in turn be used in stylistic practice. Two coda alveolar laterals described in previous work on SgE, vocalised-l and clear-l, are examples of such innovations. Coda /1/of Singaporeans tends to be vocalised, a process in which the lateral is replaced by either a (labial-)velar approximant or a back vowel or semivowel (e.g. pill [piu]). After back vowels, coda /1/ may be deleted (e.g. ball [bo: ]). Many Malay Singaporeans exhibit a different variant of coda / $/$. In his examination of the English production of ten educated Singaporean English-Malay simultaneous/ early sequential bilinguals between the ages of 19 and 28, Sim (2019) found that Malay-dominant subjects used predominantly clear-1

syllable-finally. Sim posited that, rather than this being an effect of cross-linguistic influence, clear1 could have been learned through the input, similar to British Asians (e.g. Kirkham, 2017; Sharma, 2011). Their maintenance and use of coda clear-l could also be motivated by socialindexical reasons; Sim's Malay-dominant subjects were associated with more Malay-dominant families and social circles, and identified more with a more Malay-speaking culture. While the present paper is not concerned with the aetiology of these two variants, the phonological or phonetic properties of the substrate languages could have contributed to their emergence: Chinese languages do not allow coda laterals, and while Malay has voiced alveolar laterals syllable-finally, they are always clear, in all syllable positions. No study has yet examined the / $/$ of Indian Singaporeans, but descriptions of Indian English and also studies on British Asians of South Asian heritage show that clear-l and also retroflex [ $l]$ are variably used syllable-finally 
(Sailaja, 2009; Sharma, 2011). While it cannot be assumed that clear-l is also used by Indian Singaporeans, the potential for the clear variant to also be associated with them in this study is not disregarded.

Despite a largely stabilised local norm in Singapore, features belonging to an established standard varieties of English are often regarded as prescriptively correct. The variant of /1/ associated with these standards would be dark-1. Just as Received Pronunciation (RP, Agha, 2003) and Putonghua (Dong, 2010) were enregistered as standard and a status emblem, enregisterment of an 'internationally-acceptable' English in Singapore as legitimate and the appropriate norm is facilitated through many state-motivated metadiscursive practices that reinforce its indexical values, such as in classroom instruction, media, political speeches, and government campaigns, most notably the 'Speak Good English Movement' (Rubdy, 2001). At the same time, the local varieties and their divergent features are enregistered as incorrect or nonstandard. Such enregisterment of social meanings can transform into socialised habits of speech perception and production. Recent variationist models of SgE (see Leimgruber, 2013, pp. 23-63, for a discussion) describe language use based on the social-indexical meanings of alternative forms of a linguistic feature (e.g. Alsagoff, 2007; Leimgruber, 2013). Depending on the speaker, listener and context of their use, variants that are associated with standard varieties of English can be used to index formality, authority, and educational attainment. Contrastingly, local dialectal features, which include 'Singlish' and ethnic markers, embody sociocultural capital and often index informality, camaraderie, and group membership.

\subsection{Multiplicity of interpretations}

Matched-guise studies that involved $\mathrm{SgE}$ varieties revealed that attitudes are not homogenous amongst Singaporeans, and guises of more colloquial varieties (which included standard-local accents more generally) did not index solidarity traits for all as one would expect (Cavallaro \& Chin, 2009; Cavallaro, Ng, \& Seilhamer, 2014). Indeed, indexical meanings can vary even for members within a community, based on their personal experiences with their particular sociolinguistic worlds. In their study of monophthongal / aw/ in Pittsburgh, Johnstone \& Kiesling (2008) found that those who heard monophthongal / aw/ as indexing local identity were least likely to use it in unselfconscious speech, and many of those who did use it did not identify it as indexing localness. Locals also attributed higher-order indexical meanings, if they did so at all, to local forms in different ways. The findings show that while a feature may be statistically associated with a particular sociodemographic group or context, it cannot be assumed that the indexical meaning is widely shared with or is the only meaning to members of a community. In another study, Campbell-Kibler (2008) showed that listeners' overall impression of a speaker affects how they interpret the variable (ING) (the alternation between word-final -in [In, an] and -ing [In]) in 
the person's speech; some regarded the -in guise as compassionate, while some others, condescending. She added that the "differences of opinion relate not to disagreements about (ING) alone, but to a difference in how the listeners incorporate their understanding of the variable into their image of the speaker" (p.638).

Agha (2003) noted that the specific ways a hearer characterises a variant, and therefore also the degree of access to the social meanings of these variants the hearer has, depend on their experiences and their history of socialisation to these contrasts. In socioculturally complex societies like Singapore, there is evidently even greater potential for social meanings to be diverse and subject to different interpretations, in part due to the variation in speaker and listener attributes. Bilingual experience is highly varied, and so are language outcomes, and therefore some speakers or a subpopulation may produce certain features more frequently than others in the community it indexes. Sim (2019), for instance, found that, in spontaneous speech, Malaydominant Malays used coda clear-l predominantly, while their English-dominant counterparts used dark-l most of the time. In his examination of l-vocalisation in the speech of educated Chinese Singaporeans, Tan (2005) found that the percentage of l-vocalisation (compared to dark-1) varied significantly between speakers, ranging from 39\% to $89 \%$. Depending on the hearer and his or her experiences, variants can be characterised in many ways; clear-l, for example, can be associated with non-Chinese, Malay, Malay-dominant Malay, and may further evoke images of various related subgroups/subcultures of the community, and thereby also influencing the social meanings that these hearers apply to the variants.

\subsection{Current objectives}

The primary aim of this study is to explore the accrued social-indexical meanings of these three variants of /1/ in Singapore English against the backdrop of the various socio-historical and political processes that have shaped them. Specifically, the study examines whether these variants are associated with specific ethnic communities in Singapore, with the subcommunities or particular social types they index-if any, and the social interpretation of them. The analysis also considers the diversity in listener attributes that can result in variation in the interpretation of these variants. Clearly, the lived experiences of individuals in such complex societies can differ in myriad ways. Considering that the relationship between the variants can be described as between standard-nonstandard and mainstream-ethnic, as a starting point, hearer attributes that may influence attitudes towards standard/nonstandard variants (e.g. Cavallaro \& Chin, 2009; Cavallaro et al., 2014) and factors that could differentiate their varying degrees of access to the various variants in their linguistic environment (e.g. Sim, 2019) were considered. These include age, education level, gender, ethnicity, cultural affiliation, amount of interaction with Singaporeans of different ethnicities, and language use/preferences. 


\section{Methodology}

The study was based on the matched-guise technique (MGT), which elicits listeners' reactions to various recordings, or guises, by the same speaker(s) that differed only in the variables of interest.

\subsection{Stimuli}

The creation of the stimuli was constrained by the many inter-ethnic differences in other linguistic features such as intonation and vowel quality (Deterding, 2007b; Lim, 2000) which, if acoustically manipulated, could render the stimuli highly unnatural. Therefore, the stimuli were monosyllabic words instead of sentences or short paragraphs. They also came from two speakers of different ethnicities, one who was Malay and the other Chinese, as a means to account for potential variation in speech features other than those informed by previous studies, such as voice quality. Both speakers were born and raised in Singapore and were English-dominant. The Malay speaker was a 34-year-old female, who was teaching in an English-medium school. She used Malay with her family and some friends and was still affiliated to the Malay ethnic community. The Chinese speaker was a 27-year-old female. She had limited interactions with Singaporeans of other ethnicities and therefore her overall speech features were essentially that of a typical educated Chinese Singaporean.

The materials were three pairs of monosyllabic words that were matched in their vowels (/ $, \Lambda, \mathrm{i} /)$. The pairs were: hall, fall; hull, sull; heel, feel. For each pair, the first word was read by the Malay speaker and the other by the Chinese. These words were semantically and phonologically ethnically neutral in SgE. The speakers were recorded separately in soundattenuated rooms, using a Zoom $\mathrm{H} 5$ recorder, at a sampling rate of $48 \mathrm{kHz}$ at 16 bit. The Malay speaker was first trained in producing the vocalised and dark variants by the author. The Chinese speaker, who already could produce vocalised-l and dark-l, was trained in the production of clear-l through listening to the recordings of two Malay-dominant Malays. Speakers were then asked to produce alternate tokens for the target words, each carrying a different variant of /1/. Fillers that included other ethnic features, including those specific to Indian Singaporeans, were also recorded. There was a total of 40 tokens, including fillers.

The $/ \mathrm{l} /$ tokens were first checked to ensure that they were representative of the three variants, using acoustic and auditory cues, before manipulation. Clear-l has a relatively higher F2 and low F1. The mean F2 of the clear-l tokens was $2015.26 \mathrm{~Hz}(S D=60.99)$ while the mean F2 for dark-l was $903.29 \mathrm{~Hz}(S D=85.41)$, and these values fall within the ranges that distinguish the darker and clearer variants of / $1 /$ across language varieties reported in Recasens (2012). Following previous matched-guise experiments that involved controlled stimuli (e.g. Campbell- 
Kibler, 2007; Fridland, Bartlett, \& Kreuz, 2004; Graff, Labov, \& Harris, 1986), the pitch, duration and intensity of the tokens were manipulated on Praat (Boersma \& Weenink, 2019), to limit variability between alternate tokens, such that any change in judgment of the hearers can be attributed to the different variants of $/ 1 /$. However, the coarticulatory effects of the different laterals on the vowel could not be manipulated without them sounding unnatural, and so the tokens also differed slightly in their vowel quality, but the difference is not expected to affect the judgements of the hearers. The stimuli were subsequently checked. Three linguists trained in phonetics were first asked to rate the naturalness of the tokens and to identify the variant of $/ \mathrm{l} / \mathrm{in}$ each token. Seven naïve Malays were then asked to rate the clear-l tokens on how 'Malay sounding' they were, and were asked to give reasons for low ratings. Most tokens that were rated poorly were those produced by the Chinese speaker, which were deemed by all listeners to sound more 'Indian' and were described to be 'thicker' than the Malay /1/, which could mean that there was more laminal contact with the alveolar ridge in the clear-l of the Chinese speaker. The poorly rated clear-l tokens were re-recorded and checked again, and all the clear-l tokens were rated as at least 'Probably Malay'.

\subsection{Informants}

The responses came from 111 informants recruited through social media and snowball sampling. Their basic demographics are shown in Table 1. The participants had no hearing impairment that would affect their ability to complete the task. They were mostly native Singaporeans, except for six, three of whom had been living in Singapore for at least 15 years since before they were five years old, and the other three had lived in Singapore for more than 20 years at least since they were ten years old. These six subjects were also either ethnically Chinese or Malay, and also had Mandarin or Malay as their ethnic mother tongue (EMT) respectively. In addition to their ethnicity, age, gender, and education level, all participants were asked to describe their language use pattern on a scale of 0 (only English) to 10 (only EMT), and also their cultural affiliation, again from 0 (only English-speaking) to 10 (only EMT-speaking). Finally, informants were asked to rate from 0 (never) to 10 (always) the amount of interaction they had had with Singaporeans of the three major ethnic groups (i.e. Chinese, Malays and Indians; three scores). The gender of 32 participants could not be ascertained, and the missing data were coded as a new level ('unknown') for the statistical analyses.

Table 1. Listener demographics

\begin{tabular}{lccc}
\hline Variable & $\mathbf{N}$ & Median (range) & Mean (SD) \\
\hline Ethnicity: Chinese/Malay/Indian & $65 / 36 / 10$ & & \\
\hline Age & & $30.5(18-53)$ & $30.22(7.98)$ \\
\hline
\end{tabular}




\begin{tabular}{lll}
\hline Gender: Male/Female/Unknown & $29 / 50 / 32$ & \\
\hline Education level: & & \\
\hline Secondary or below & 1 & \\
\hline Post-secondary & 16 & \\
\hline Undergraduate & 16 & \\
\hline Bachelor's & 56 & $3.03(1.75)$ \\
\hline Postgraduate & 22 & $3.66(1.99)$ \\
\hline Language use (o=English only) & & $3(0-8)$ \\
\hline Cultural affiliation (0 = English only) & $4(0-9)$ & $8.62(1.80)$ \\
\hline Interactions with (o = Never): & & $5.66(3.18)$ \\
\hline Chinese & $9(3-10)$ & $4.28(2.88)$ \\
\hline Malays & $5(1-10)$ & \\
\hline Indians & $4(0-10)$ &
\end{tabular}

\subsection{Experimental design}

The experiment was hosted on Qualtrics. Participants first underwent a headphone screening test (Woods, Siegel, Traer, \& McDermott, 2017), before attempting the experiment that comprised two parts: an ethnic association task and an attitude judgement task. In the instructions that preceded each part, participants were told that the speakers were Singaporeans.

In the ethnic association task, listeners heard each token a maximum of five times and responded to the question, "How near is the pronunciation you have just heard to what you would expect from the ethnic groups shown?" by clicking on a point on a three-way scale developed for this study (Figure 1). The scale takes into account the relativity of ethnic markedness as perceived by a listener and that a feature can potentially be perceived as shared by members of more than one ethnic group. The ends of the scales indicate a feature as being absolutely representative of the respective ethnic group, and points along the scale and away from one group indicate decreasing affiliation of the feature with that ethnic group but increasing affiliation with the other; the middle point of each side indicates that a feature is considered by a listener to be equally representative of both ethnic groups. Finally, respondents were told to choose the option in the middle of the triangle, 'Could be any', if the feature was thought to be not ethnically distinct. The tokens were pseudorandomised such that no two tokens by the same speaker and no two tokens of a word (i.e. with alternative forms) appeared consecutively. Participants completed a practice trial that consisted of two tokens before the actual task. 
HULL

- 0:00/0:07 - (1)

How near is the pronunciation you have just heard to what you would expect from the

ethnic groups shown?

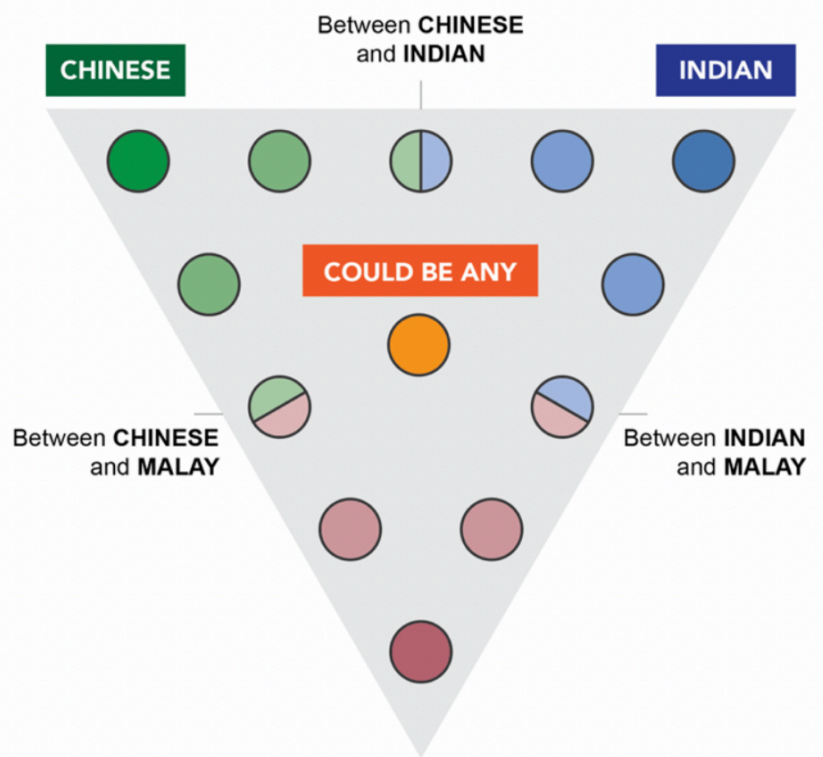

MALAY

Figure 1. A sample item from the ethnic association task.

In the attitude judgement task, participants heard the same tokens but this time the tokens were grouped according to the variant of / / , and they could listen to the sets as many times as they liked. Listeners were asked to rate each set according to five traits on a seven-point scale, namely ethnic-accentedness, formality, fluency, educatedness, and friendliness (Figure 2). The participants were also asked to rate how close they thought the pronunciation of the words was to theirs using the same scale. The selection of traits was limited by the nature of the one-word guises in this study, and therefore the informants were also asked to describe the profile of this Singaporean and/or the community that the speaker(s) is most likely to belong to in an openended response, in order to elicit other social meanings that could not be captured by these traits. 
FALL, SULL, FELL, FEEL

- 0:00/0:04

4) :

Based on how the words are pronounced, what are your opinions about this speaker(s)?

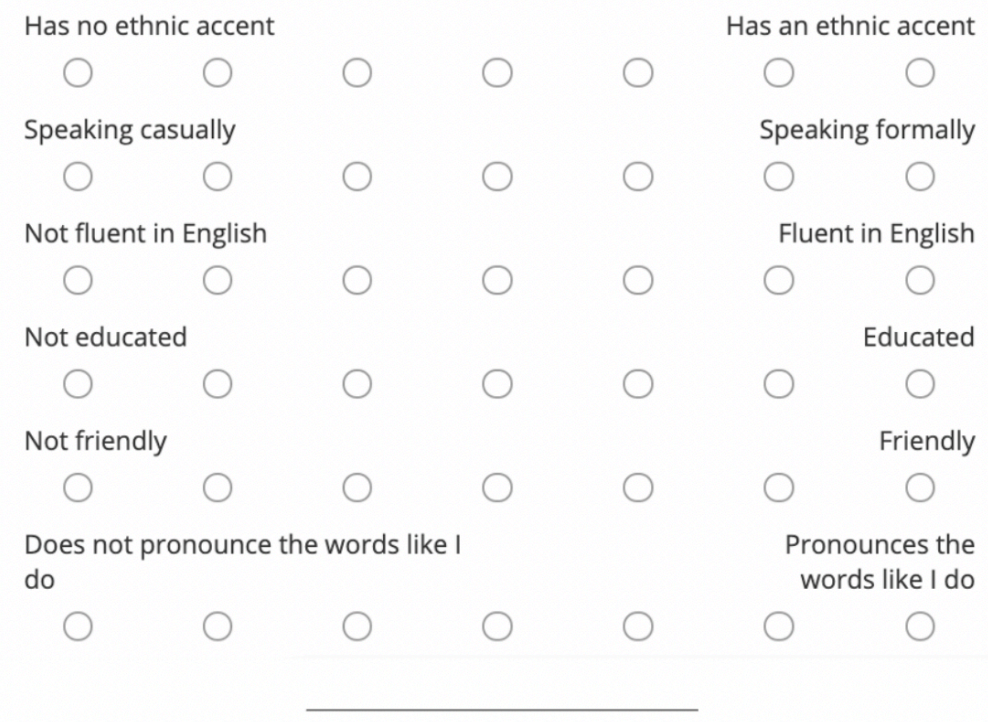

We hear different English accents by different groups or communities of Singaporeans every day. What type of Singaporeans do you think frequently pronounce these words in this way? Use some words/short phrases to describe (i) the profile of this Singaporean speaker(s) and/or (ii) the community that this speaker(s) is likely to belong to. Be honest/frank and as detailed as possible.

As the recordings are presented in a random order, avoid making reference to other recordings (e.g. "same as previous", "like the first one").

Figure 2. A sample item from the attitude judgement task.

\subsection{Metalinguistic interview}

As clear-l as a variant in $\mathrm{SgE}$ is relatively under-researched, face-to-face metalinguistic talk between the author and 11 other Malay Singaporeans was conducted in order to understand 
more about its use, associations, and its significance to the Malay ethnic community. Brief demographic information about these informants is presented in Table 2.

Table 2. Demographics of interview participants

\begin{tabular}{llllll}
\hline Subject & Gender & Age & Education level & Language use & Cultural affiliation \\
\hline F1 & Female & 22 & Bachelor's & 2 & 4 \\
\hline F2 & Female & 21 & Undergraduate & 3 & 4 \\
\hline F3 & Female & 19 & Undergraduate & 5 & 7 \\
\hline F4 & Female & 23 & Undergraduate & 3 & 5 \\
\hline M1 & Male & 21 & Undergraduate & 5 & 5 \\
\hline M2 & Male & 23 & Undergraduate & 4 & 5 \\
\hline$M 3$ & Male & 22 & Undergraduate & 3 & 3 \\
\hline M4 & Male & 22 & Undergraduate & 1 & 2 \\
\hline$M 5$ & Male & 32 & Post-secondary & 4 & 3 \\
\hline$M 6$ & Male & 31 & Bachelor's & 3 & 4 \\
\hline$M 7$ & Male & 35 & Bachelor's & 4 & 3 \\
\hline
\end{tabular}

Note: language use/cultural affiliation: o (only English) to 10 (only Malay).

\section{Results}

\subsection{Ethnic association task}

A total of 1988 responses were recorded in the ethnic association task. The percentages of ratings for each variant of / / are presented in Figure 3, using the same categories shown in Figure 1. For reasons of clarity, only percentages greater than five are shown, and a bubble chart that reflects the relative proportion of ratings for each variant is superimposed. The plots reveal that most informants associated dark-l as a pan-Singaporean feature, though equally many regarded it as at least somewhat Chinese. The reverse is true for vocalised-1; more respondents associated vocalised-l as distinctly Chinese, but many perceived it as ethnically neutral. In stark contrast, responses for clear-l fell almost exclusively along the MALAY-INDIAN scale. 
Dark-I

Vocalised-I

Clear-I
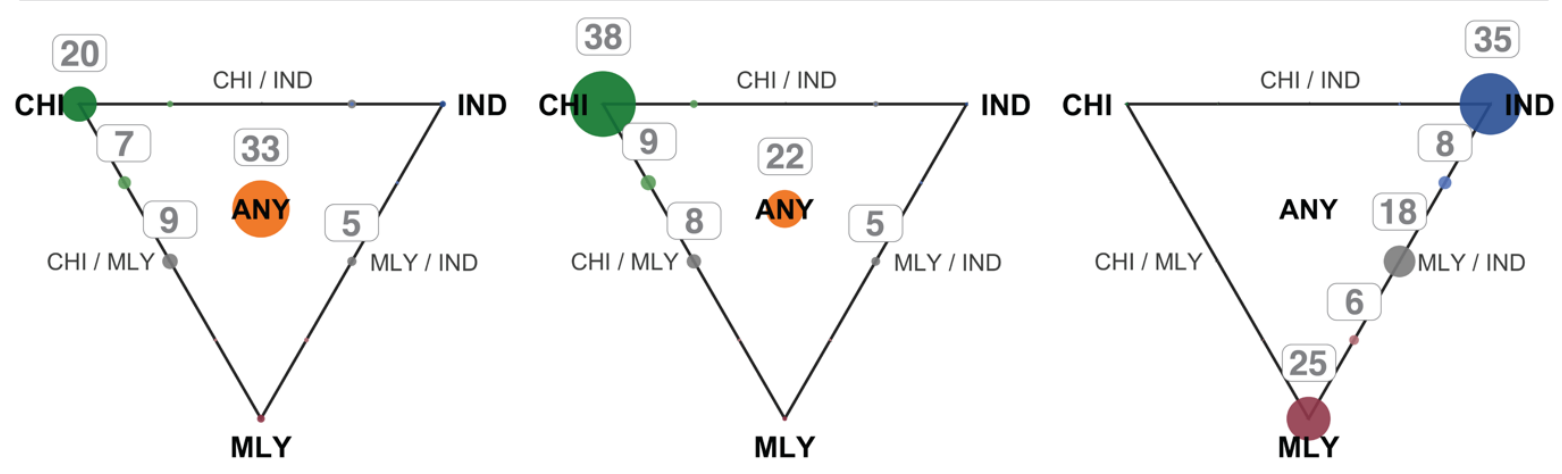

Figure 3. Percentage of responses for the ethnic association task by variant of $/ I /$. Note: Percentages are rounded to the nearest percent and only percentages above five are shown. $\mathrm{CHI}=$ Chinese, $M L Y=$ Malay, IND = Indian, ANY = Could be any.

To confirm these observations as well as to ascertain effects of listener attributes, three separate mixed-effects ordinal regression models were run using the ordinal package (Christensen, 2019) on R statistical software (R Core Team, 2020). The response was ordinal variable 'Chinese', 'Malay' or 'Indian'. Ratings of 'Could be any' were excluded from this analysis. Ratings were first transformed to numerical values, starting at ' 4 ' for the end of the scale that corresponds to the response variable of interest, to ' 0 ' at the other two ends, and ratings for categories in between were given the values ' 3 ', ' 2 ', and ' 1 ', according to numerical order; the magnitude of the ratings is thus positively associated with the ethnic affiliation of a feature. The random effects structure was kept maximal for subject and token, as justified by the data. The fixed effects included variant (dark/vocalised/clear), speaker (Chinese/Malay), ethnicity (Chinese/Malay/Indian), gender (female/male/unknown), age, education level (treated as a continuous variable), degree of interaction with Singaporeans of the ethnicity of interest (Int_x), language use, and cultural affiliation, and the two-way interactions between all main effects. To evaluate the contribution of each predictor, and to arrive at a more restricted model, pairwise model comparisons between a full model that included all the explanatory variables and a more restricted model that excluded the predictor under consideration were performed using likelihood ratio tests. The results of the best-fitting models are presented in Table 3. 
Table 3. Regression coefficients of best-fitting mixed-effects regression models fit to responses of the ethnic association task

\begin{tabular}{|c|c|c|c|c|c|c|c|}
\hline Response $(N)$ & Fixed effects & Level & B & SE & OR & {$[95 \% \mathrm{Cl}]$} & $p$ \\
\hline Chinese & Variant & Clear & -5.80 & 0.62 & 0.00 & $0.00-0.01$ & $<.001$ \\
\hline \multirow[t]{4}{*}{ (1625) } & & Vocalised & 0.96 & 0.20 & 2.61 & $1.75-3.89$ & $<.001$ \\
\hline & Speaker & Malay & 0.71 & 0.32 & 2.03 & $1.09-3.79$ & .03 \\
\hline & Ethnicity & Indian & 1.02 & 0.44 & 2.78 & $1.18-6.55$ & .02 \\
\hline & & Malay & 0.05 & 0.21 & 1.05 & $0.70-1.57$ & .81 \\
\hline Malay & Variant & Clear & 0.80 & 0.30 & 2.23 & $1.24-4.01$ & .01 \\
\hline \multirow[t]{7}{*}{ (1625) } & & Vocalised & -0.35 & 0.23 & 0.71 & $0.45-1.12$ & .14 \\
\hline & Ethnicity & Indian & -2.21 & 0.72 & 0.11 & $0.03-0.45$ & .002 \\
\hline & & Malay & 0.32 & 0.26 & 1.37 & $0.83-2.26$ & .21 \\
\hline & Variant $\times$ Ethnici & Clear:Indian & 2.70 & 0.82 & 14.81 & $2.98-73.49$ & .001 \\
\hline & ty & Voc:Indian & 1.06 & 0.63 & 2.88 & $0.85-9.82$ & .09 \\
\hline & & Clear:Malay & -0.34 & 0.42 & 0.71 & $0.31-1.64$ & .43 \\
\hline & & Voc:Malay & -0.70 & 0.32 & 0.50 & $0.26-0.94$ & .03 \\
\hline Indian & Variant & Clear & -0.64 & 0.81 & 0.53 & $0.11-2.58$ & .43 \\
\hline \multirow[t]{5}{*}{ (1625) } & & Vocalised & -0.81 & 0.65 & 0.44 & $0.12-1.59$ & .21 \\
\hline & Speaker & Malay & -0.76 & 0.32 & 0.47 & $0.25-0.86$ & .02 \\
\hline & Age & & -0.03 & 0.02 & 0.97 & $0.93-1.00$ & .08 \\
\hline & Variant $\times$ Age & Clear:Age & 0.09 & 0.03 & 1.10 & $1.04-1.15$ & $<.001$ \\
\hline & & Voc:Age & 0.001 & 0.02 & 1.00 & $0.96-1.04$ & .96 \\
\hline Malay-Indian & Speaker & Malay & 0.55 & 0.27 & 1.73 & $1.01-2.96$ & .04 \\
\hline \multirow[t]{3}{*}{ (612) } & Int_Malay & & 0.14 & 0.07 & 1.15 & $1.00-1.33$ & .04 \\
\hline & Int_Indian & & -0.09 & 0.08 & 0.91 & $0.78-1.06$ & .21 \\
\hline & Age & & -0.06 & 0.02 & 0.94 & $0.90-0.98$ & .01 \\
\hline Any & Variant & Clear & -5.77 & 0.82 & 0.00 & $0.00-0.02$ & $<.001$ \\
\hline \multirow[t]{3}{*}{ (1998) } & & Vocalised & -0.69 & 0.29 & 0.50 & $0.29-0.89$ & .02 \\
\hline & Age & & -0.09 & 0.03 & 0.91 & $0.87-0.96$ & $<.001$ \\
\hline & Education & & 0.45 & 0.21 & 1.57 & $1.05-2.34$ & .03 \\
\hline
\end{tabular}

Note: $\mathrm{OR}=$ odds ratio; $\mathrm{Cl}=$ confidence interval; $\mathrm{SE}$ = standard error. Reference category for variant is dark, speaker is Chinese, ethnicity is Chinese.

In the best-fitting model for 'Chinese', the main effects of variant, speaker, and ethnicity were significant predictors. Compared to dark-l, clear-l was less likely to be given higher ratings of CHINESE, whereas vocalised-l increased ratings. Interestingly, compared to the Chinese speaker, the Malay speaker was more likely to be rated more CHINESE. In addition, compared to Chinese listeners, Indian respondents were overall more likely to give guises higher ratings of CHINESE. In the model for 'Malay', the main effects of variant, ethnicity, and their interaction were significant predictors. Compared to dark-l, guises with clear-l were significantly more likely to increase ratings of MALAY, whereas guises with vocalised-l were less likely to be given higher ratings, although this difference was not significant, perhaps due to interaction effects. The interaction between variant and ethnicity were explored using plots of marginal means and pairwise 
comparisons (with Tukey adjustments) using the emmeans package (Lenth, 2020). The analysis revealed that clear-l was more likely to be given higher ratings of MALAY than dark-l for Chinese and Indian informants, but the difference for Malay listeners was not significant, which suggests that many Malay listeners gave dark-l similar ratings of MALAY as they gave clear-l. In addition, contrasts by variant of / $/$ showed that compared to Chinese and Malay listeners, Indian listeners were more likely to give dark-l lower ratings of MALAY. Finally, in the model for 'Indian', the main effects of speaker and the interaction between variant and age were significant predictors. The Chinese speaker was more likely to be given higher ratings of INDIAN. The interaction term was explored using spotlight analysis to find out how ratings of variant varied by three levels of age: at the mean level, +1 SD, and at -1 SD. The analysis revealed that, while clear-l was overall more likely to increase ratings of INDIAN compared to dark-l for all age levels, older listeners were more likely to rate clear-l in higher ratings of INDIAN than younger listeners.

Since clear-l was revealed to be strongly associated with both Malay and Indian Singaporeans, additional ordinal regression analysis was performed on only clear-l tokens and ratings along the scale of MALAY-INDIAN. Ratings were changed from '4' (MALAY) to '0' (INDIAN). The random effects structure was kept maximal for subject and token. The same fixed effects as the previous models were included (but excluding variant) and categorical variables were treatment coded with the same reference levels. The reduced model ('Malay-Indian', presented in Table 3) revealed that the main effects of speaker, amount of interaction with Malays, and age were significant predictors. Compared to the Chinese speaker, the Malay speaker was more likely to be given higher ratings, i.e. more 'Malay'. Regardless of ethnicity, informants who reported higher degree of interactions with Malays were more likely to give clear-l higher ratings of MALAY. Finally, age was negatively associated with the ratings, i.e. more 'Indian', an effect also observed in the previous 'Indian' model.

The response 'Could be any' was modelled using mixed-effects generalised linear regression using the lme4 package (Bates, Mächler, Bolker, \& Walker, 2015) and the lmerTest package (Kuznetsova, Brockhoff, \& Christensen, 2017). The random effects structure was kept maximal for subject and token. The same predictors as the previous main models were included and categorical predictors were treatment coded with the same reference levels. The results for the best-fitting model are also presented in Table 3 ('Any'). In the best-fitting model, the main effects of variant, age, and education were significant predictors. Compared to dark-1, both clear-1 and vocalised-1 were less likely to be rated COULD BE ANY. The likelihood of a token being rated as COULD BE ANY was negatively associated with the age of respondents, but positively associated with education level. 


\subsection{Attitude judgement: rating task}

The results of the attitude rating task are presented in Figure 4 in terms of relative proportions in a percent stacked barplot, as a function of variant and trait. By visual inspection, dark-l appears to have been given greater proportion of ratings above ' 4 ' for educatedness, fluency and formality than the other two variants. Vocalised-l and clear-l did not seem to differ greatly in the ratings for these three traits, and listeners were divided in their opinions. Amongst all variants, clear-l was rated the most ethnic-accented and also the friendliest.
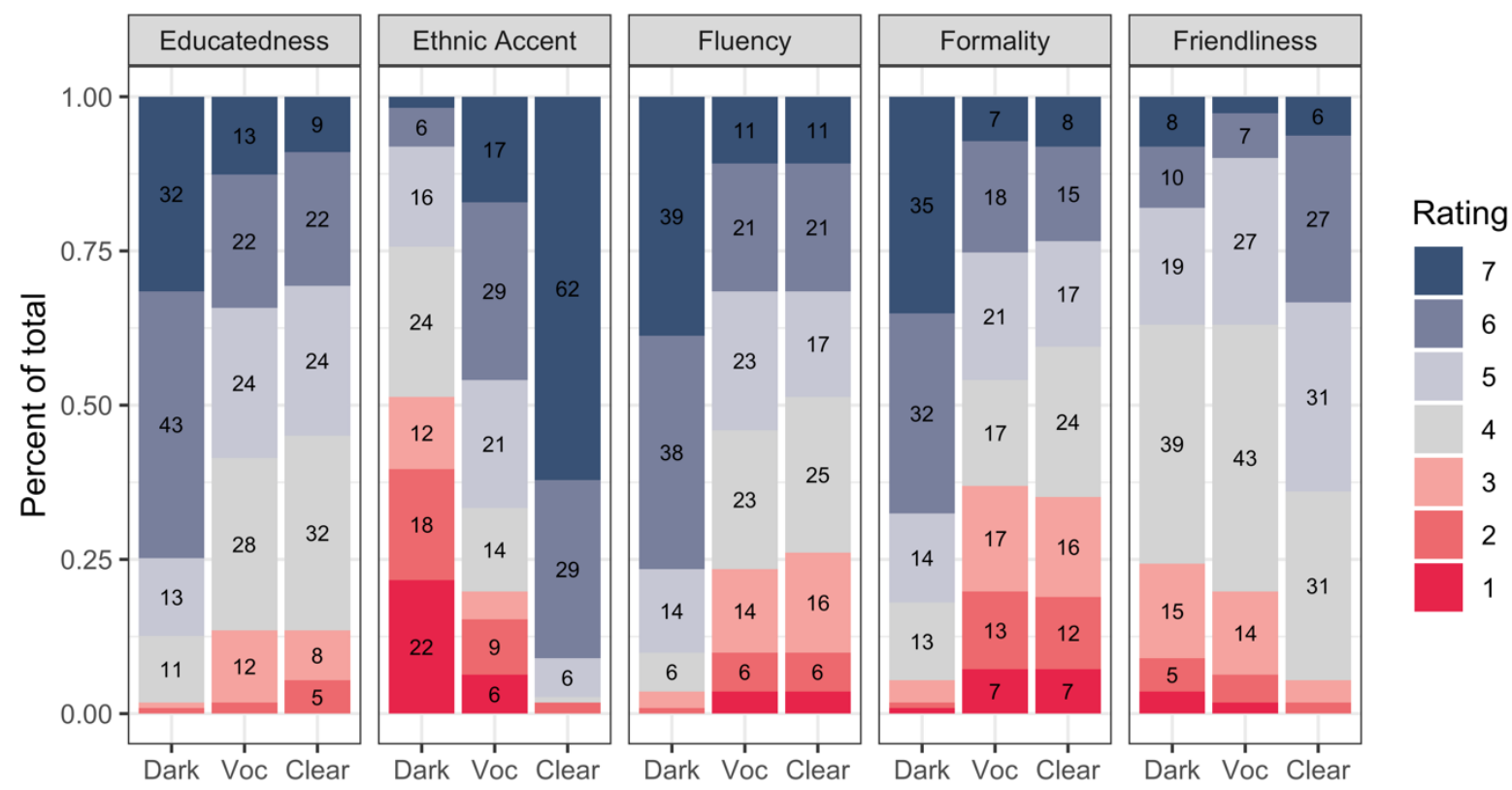

Variant

Figure 4. Percentages of responses for the attitude rating task as a function of trait and variant of $/ / /$. Note: Percentages are rounded to the nearest percent and only percentages above five are shown.

Regression analysis was performed to confirm these observations and to ascertain effects of listener attributes. Considering that some traits may be correlated, principal component analysis was first conducted with orthogonal rotation (varimax) to create index variables. The components were evaluated using the Kaiser criterion and parallel analysis, and two factors met the criteria: a 'status' factor (loading for educatedness, fluency, formality, and ethnic accent) and a 'friendliness' factor, which consisted of friendliness alone. The two factors in combination accounted for $74 \%$ of the variance.

For all regression models, the random effects structure was kept maximal for subject. The fixed effects included variant, ethnicity, age, education level, gender, degree of interactions with Singaporeans of other ethnicity (three separate scores), language use, cultural affiliation, 
perceived similarity, and two-way interactions between variant and other main effects. The results for the best-fitting models are presented in Table 4.

In the best-fitting model for 'status', the main effects of variant, similarity, and the two-way interactions between variant and education, and between variant and language use were significant predictors. Compared to dark-l, both clear-l and vocalised-l were less likely to be given higher ratings of status. Perceived similarity was positively associated with status ratings. In the interaction between variant and education, plots of marginal effects revealed that informants who were more educated were more likely to give clear-l and vocalised-l higher ratings of status than listeners who were less educated, but the reverse is true for status ratings of dark-l. Spotlight analysis of the interaction between variant and language use revealed that overall across ratings, listeners who were less English dominant in terms of language use were more likely to give vocalised-l higher ratings of status.

In the model for 'friendliness', the main effects of variant, similarity and gender were significant predictors. Compared to dark-l, clear-l was more likely to be given higher friendliness ratings. Friendliness ratings were also positively associated with perceived similarity. Finally, male informants were more likely to give the guises overall lower friendliness ratings than female informants. 
Table 4. Regression coefficients of best-fitting mixed-effects ordinal regression model fit to responses of the attitude rating task

\begin{tabular}{|c|c|c|c|c|c|c|c|}
\hline Response (N) & Fixed factors & Level & B & SE & OR & {$[95 \% \mathrm{Cl}]$} & $p$ \\
\hline Status & Variant & Clear & -2.11 & 0.66 & 0.12 & $0.03-0.44$ & .001 \\
\hline \multirow[t]{8}{*}{ (1332) } & & Vocalised & -2.72 & 0.66 & 0.07 & $0.02-0.24$ & $<.001$ \\
\hline & Education & & -0.20 & 0.12 & 0.82 & $0.64-1.04$ & .11 \\
\hline & Language use & & -0.02 & 0.07 & 0.98 & $0.86-1.11$ & .71 \\
\hline & Similarity & & 0.24 & 0.04 & 1.27 & $1.17-1.38$ & $<.001$ \\
\hline & Variant×Education & Clear:Edu & 0.37 & 0.14 & 1.44 & $1.09-1.91$ & .01 \\
\hline & & Voc:Edu & 0.32 & 0.14 & 1.37 & $1.03-1.82$ & .03 \\
\hline & Variant×Language & Clear:Use & -0.04 & 0.08 & 0.96 & $0.82-1.12$ & .58 \\
\hline & use & Voc:Use & 0.16 & 0.08 & 1.17 & $1.00-1.37$ & .04 \\
\hline \multirow{5}{*}{$\begin{array}{l}\text { Friendliness } \\
\text { (333) }\end{array}$} & Variant & Clear & 1.73 & 0.32 & 5.62 & $3.02-10.44$ & $<.001$ \\
\hline & & Vocalised & 0.13 & 0.27 & 1.14 & $0.68-1.93$ & .62 \\
\hline & Similarity & & 0.19 & 0.08 & 1.21 & $1.04-1.40$ & .01 \\
\hline & Gender & Male & -1.12 & 0.38 & 0.33 & $0.16-0.68$ & .003 \\
\hline & & Unknown & -0.53 & 0.36 & 0.59 & $0.29-1.20$ & .14 \\
\hline
\end{tabular}

Note: $\mathrm{OR}$ = odds ratio; $\mathrm{Cl}=$ confidence interval; $\mathrm{SE}$ = standard error. Reference category for variant is dark, gender is female.

\subsection{Attitude judgement: open-ended question}

Open-ended responses for dark-l, vocalised-l and clear-l are summarised in Table 5, Table 6 and Table 7 respectively.

The responses for dark-l are grouped according to the speakers it indexes, the contexts or practices in which it is thought to be commonly used or occur, and its associated qualities. Although a slight majority associated dark-1 with Chinese Singaporeans, many regarded it as a pan-Singaporean feature. The variant was unanimously positively evaluated by all listeners. The speakers that dark-l indexed were the young, well educated, English-dominant Singaporeans from higher social classes, and native speakers or angmohs, which is a mildly derogatory term to refer to Caucasians. The variant was considered correct/accurate and standard, and thought to belong to be part of the style used in contexts where formal and careful speech is expected. However, a handful commented that the speaker was cold in her emotions or trying hard to speak good English. 
Table 5. Open-ended responses for dark-I

\begin{tabular}{lll}
\hline Speakers & Contexts & Qualities \\
\hline Well-educated & Oral examination & Standard \\
Chinese & Interview & Accurate/careful \\
English-dominant & Presentation & Trying hard/cold \\
Any race & & Dictionary pronunciation \\
Customer-facing jobs & Formal \\
Lived/studied abroad & \\
Indian/Malay & & \\
Young & & \\
High social class & & \\
Educator/teacher & & \\
English-dominant peers & & \\
Caucasian/Angmoh/native speaker & & \\
\end{tabular}

Listeners across ethnicities shared similar social opinions towards vocalised-l, but a sizeable minority had differing views. These opposing views are presented in Table 6. For many (Group A), vocalised-l indexed Singaporeans who are Chinese-dominant/L2 speakers, middle-aged, less educated, and using colloquial English. The variant was associated with similar social types, for example auntie, a local cultural term that may refer to middle-aged women who are often lowlyeducated, Chinese-educated and old-fashioned in their ways of thinking (Wong, 2006). For some, vocalised-l evoked even more specific social types like housewives or caifan auntie, who are aunties that sell 'economy rice' in hawker centres. For some others (Group B), vocalised-l was associated with young, middle-class, well-educated Singaporeans and working professionals. They also regarded the pronunciation to be good articulation and standard, and belong to a style used in formal settings.

Table 6. Open-ended responsesfor vocalised-I

\begin{tabular}{ll}
\hline Group & \\
\hline A & B \\
\hline Chinese-dominant & Chinese/Malay/Indian \\
Middle-aged & Young \\
Less educated & Well educated \\
L2 speaker & Good articulation/enunciation \\
Colloquial & Standard/Formal \\
Auntie/housewife/'Caifan auntie’ & Working professional \\
Average Singaporean & Middle class \\
\hline
\end{tabular}

The open-ended responses for clear-l in Table 7 are presented according to the ethnicity of the listeners. Some traits and attributes were dependent on whether the speaker was perceived to be 
Malay (M) or Indian (I), as indicated in the table. Compared to vocalised-l, the responses for clear-l were less divergent. Chinese listeners generally associated clear-l with EMT-dominant/L2 speakers and less educated minorities from lower social classes. Malay respondents from both the online survey and metalinguistic talk, however, asserted that while many users of clear-l are Malay-dominant, it is not exclusively used by less educated Malays or those form lower social classes. Those interviewed apointed out that Malays who are highly educated and proficient in English may also use clear-l in casual situations or to index group membership:

“... we only use it when talking to our friends, like casual ...; among my group of Malay friends, that's how we talk to each other." (M3)

"...some kid actually got mad at me because I sounded really English-sounding compared to him ... I know if I were to be like be a stereotypical Malay ... I need to speak differently ... when I do hang out with the more Malay Malay, that's when the Malayness comes out."(M6)

When the speakers were perceived as Malay, listeners associated the variant with several related social types. One of which is minah, a Malay word that means Malay girl, which is sometimes used interchangeably with minah-rep to refer to female Malay-dominant gangsters/delinquents who are usually uneducated and unruly. Clear-l was also associated with makciks, who are the Malay equivalent of Chinese aunties, and again in some listeners more specific social types were evoked, such as housewife or 'nasi briyani auntie', which is loosely the Malay equivalent of a 'caifan auntie'. To one of the Malay respondents interviewed (M7), his involvement in the Malay arts and cultural scene let him to associate the use of clear-l with jiwang, a Malay expression to mean 'overly sentimental' or lovesickness, as well as the multiple art forms that evoke this emotion, such as Malay love poems and soft-rock love ballads, or even personae like mat/minah jiwang-a Malay boy or girl who is overtly romantic/sentimental. Interestingly, opinions were different when the speakers were perceived to be Indian in ethnicity. Towards Chinese informants, an Indian who uses clear-l is regarded to be well-educated and speaking in a formal setting. Similarly, Indian listeners thought that an Indian speaker who uses clear-l is dominant in her EMT yet is educated and middle class, although a few added that the speaker must either be a foreigner or have been raised abroad. 
Table 7. Responses from open-ended question and metalinguistic interview for clear-I

\begin{tabular}{lll}
\hline Ethnicity of listener & & \\
\hline Chinese & Malay & Indian \\
\hline Indian/Malay & Indian/Malay & Indian/Malay \\
EMT-dominant & EMT-dominant & EMT-dominant-(I) \\
L2 speaker & Young & Foreigner/raised abroad-(I) \\
Thick accent-(I) & Thick accent & Speaking with family-(M) \\
Well educated-(I) & EMT-dominant peers & Educated-(I) \\
Less educated & Minah-rep-(M) & Middle class-(I) \\
Middle-aged & Jiwang-(M) & \\
Young & & \\
Formal-(I) & & \\
Low-middle class-(I) & & \\
Minah-(M) & & \\
Makcik/housewife/'Nasi Briyani & & \\
\multicolumn{1}{c}{ auntie'-(M) } & & \\
\hline
\end{tabular}

Note: $(I)=$ only if speakers were perceived to be Indian; $(M)=$ only if speakers were perceived to be Malay.

\section{Discussion}

The findings confirmed that listeners in this study were more likely to associate the two variants that arose from language contact to the ethnic groups whose other language(s) may have had an influence on their emergence; vocalised-1 was more likely to regarded a feature of Chinese Singaporeans, and clear-l was exclusively associated with Malay/Indian Singaporeans. Contrastingly, dark-l, which is associated with prescriptive standards, was more likely to be regarded as a pan-Singaporean feature. The attitude judgement tasks revealed that dark-l was given higher ratings on status traits such as educatedness, fluency and formality, whereas clear-l was given higher friendliness ratings. As predicted, the evaluations of the variants were not uniform across hearers; several listener attributes were found to significantly modulate ethnic associations of and attitudes towards the variants, and open-ended responses revealed that each variant was associated with a variety of social groups/types, qualities and contexts. The following first discusses the social meanings of the variants and the meaningful predictors that have influenced their interpretation, before describing how the results of this study inform current approaches to studying variation that are based on indexicality.

That dark-l was unanimously accorded social prestige by the listeners in this study and evoked semiotic connections to education, high social status and formality is not unexpected; the findings are aligned with other studies that evaluated perceptions of standard/nonstandard features (e.g. Chappell, 2016). As mentioned earlier, social regularity of recognition of language ideals in Singapore is realised through the ideological process of enregisterment, similar to how public perceptions towards RP and Putonghua are shaped (Agha, 2003, 2007; Dong, 2010). This 
public awareness of the social value of standard English has been observed in the attitudes towards varieties of Singapore English in past research (e.g. Cavallaro \& Chin, 2009; Cavallaro et al., 2014), and it is shown here that such attitudes extend to specific speech forms. In this study, the ratings of status traits were also found to interact with the education level of the informants; listeners who were more educated were more likely to give clear-l and vocalised-l higher ratings of status than listeners who were less educated, and the reverse is true for dark-l. Cavallaro et al. (2014) reported similar findings. Based on their interview responses from 133 Singaporeans, they found that participants with university education expressed more favourable views towards colloquial Singapore English than those without university education. Cavallaro and colleagues surmised that those who had fewer opportunities to acquire proficiency in the standard variety might have more positive views towards it for the social mobility that it promises.

The sociohistorical processes that shaped vocalised-l and clear-l, which are variants that arose from language contact, have resulted in diverse social meanings, notably in how they indexed multiple social types from different age groups. Yet, their meanings may not have evolved in the same way. Clear-l still largely indexes the same profile of speakers from whom the variant may have originally emerged (i.e. EMT-dominant/L2 speakers) and evokes mainly less positive attributes (e.g. less educated/lower social class). While the same social meanings apply to vocalised-l, many perceived the variant to be a pan-Singaporean feature, less ethnic-accented, and associated with well-educated, middle-class Singaporeans and those speaking in standard English or formally. These divergent interpretations may point to an emerging local standard. This could be due to the hearers' inability to differentiate vocalised-l and dark-l, despite the efforts to ensure that the guises used in this experiment were adequately distinct and 'canonical'. A more likely explanation is that vocalised-l has become the dominant variant over time by virtue of the number of speakers who use it, even by educated Singaporeans and in formal contexts (Deterding, 2007a; Tan, 2005), and had therefore gain new social meanings that were once exclusive to dark-l. Against this baseline, clear-l became more salient/ethnically-marked and less standard; inevitably, ethnic minorities who use clear-l are more likely to be prejudiced and negatively evaluated.

However, unlike the communities in which dialect levelling is observed or where the speech of minority or heritage speakers converges to the dominant norm, here, clear-l is preserved for socially purposeful work. It is still the unselfconscious variant used predominantly by older generation of Malays who are L2 speakers and younger generation of L1 speakers of English who have acquired it from the input of caregiver or peers (Sim, 2019). Metalinguistic talk with the 11 Malay respondents revealed that clear-l is also used variably by Malay non-users, especially males, as part of their ethnolinguistic repertoire to signal group membership, in ways similar to British Asians (Kirkham, 2017; Sharma, 2011). That different variants of / / are used within the ethnic community is recognised by Malay listeners in this study, who gave clear-l and dark-l similar ratings of 'Malayness', which reflects actual production data (Sim, 2019). This 
awareness, however, was not shared by listeners of other ethnicities, who gave significantly lower ratings of MALAY for dark-l. Likewise, while English-dominant and/or educated Malays do use clear-l, the variant was only stereotypically associated with the Malay-dominant and less educated. These findings show how the interpretation of social meanings is dependent on and shaped by individual experiences with the sociolinguistic world, a point that will be revisited in the next section. Another finding related to clear-l supports previous findings that showed that social perceptions are also context dependent (e.g. Pharao, Maegaard, Møller, \& Kristiansen, 2014; Walker et al., 2014). Campbell-Kibler (2009), for example, found that the use of -in decreased speakers' ratings of education and intelligence only when they were perceived to be from a working-class background. Here, it was revealed that the speakers of clear-l were regarded as less educated and informal if they were perceived to be Malays, but well-educated, middle-class, and formal if perceived to be Indians. It is uncertain, however, whether Indians do indeed use clear-l, given that at present little is known about the / / used by Indian Singaporeans. In fact, those who rated clear-l as INDIAN may have made generalisations based on their prior, vague linguistic knowledge on other attributes of the speech of Indian Singaporeans (e.g. "The way Indian ... speaks has a certain twang and slang to it."). Some findings of this study may suggest that the / $/$ used by Indian Singaporeans is different. First, the clear-l guises of the Malay speaker were rated as more MALAY than the Chinese speaker, which may reflect subtle but perceivable differences in their realisations. This is supported by how informants who reported higher degree of interactions with Malay Singaporeans thought that clear-l was more MALAY. Second, older Singaporeans were found to be more likely to give higher ratings of INDIAN for clear-l, and this may suggest that older-generation Indians might have used clear-/retroflex-l more frequently than is the case now. Further empirical work can be done to confirm these postulations.

\subsection{Meanings through different lenses}

Hearers in this study were revealed to have different and sometimes conflicting evaluations of the variants. This may be due to hearer biases; in this study, for example, ratings of perceived similarity were positively associated with status and friendliness ratings. Those who were less English-dominant, and therefore presumably more likely to use vocalised-l, gave vocalised-1 higher status ratings. Differences could also be due to hearers' individual experiences. Meaningform associations are created and reinforced in different ways, to different extents, and for different people (Agha, 2007; Campbell-Kibler, 2008; Johnstone \& Kiesling, 2008). For some hearers in this study, these experiences lasted only very briefly, with a limited group of individuals, and in restricted contexts. But for others, their experiences may occur in more wide-ranging contexts, and over longer periods of time. Vocalised-l, for instance, evoked very specific encounters with the variant for some hearers (e.g. "Reminds me of my Chinese colleague."), but 
elicited broader generalisations and stereotypes for others (e.g. "I think it is typical of Chinese people, no matter how educated they are."). The ways Singaporeans are socialised to these variants are further modulated by variation in speaker attributes, such that each / / variant can index multiple social types/groups, thereby evoking very diverse attributes and values.

However, it is proposed here that these seemingly diverse or even conflicting meanings can be described to be interrelated in a highly complex network and linked by various social factors as they are created, and the myriad interpretations are but fragments of a whole sociolinguistic reality, as observed through the lenses of the hearer. Figure 5 is an example of how some of the Malay-related indexical meanings that were observed for clear-l are connected. In this network, social groups/types are linked by increasingly broader, super-ordinate categories (e.g. nasi briyani auntie $<$ makciks $<$ Malay-dominant $<$ Malay $<\ldots$ ), and distinct or conflicting traits and qualities associated with higher-order categories are reconciled by lower-order categories that are shared (e.g. minahs and makciks are linked by their being Malay-dominant). Meanings that are not directly linked may also be evoked based on their distant associations; minahs may be assumed to be raised by makciks in Malay-dominant families, for instance, and they are associated with expressions of jiwang. The interpretation of a variant is dependent on and reinforced by the hearer's experiences with the various parts of the network and its user(s) and contexts, which may change or expand according to the other speakers and different contexts in which the variant is again encountered. For one, the social perception of clear-l may be limited to the nasi briyani auntie that they buy food from, but for another, the meanings of clear-l accumulate from the dayto-day interactions with their Malay neighbours. Therefore, in the same way that hyperarticulated $/ t /$ release can index different social types and semantically related qualities in different communities (Eckert, 2008a), alternative variants of a feature in sociolinguistically and socioculturally complex societies like Singapore can index diverse social meanings that are socially related within the community. This has far-reaching implications for a plural society, as one's experiences with the social world or a lack thereof can result in accent-based prejudices or stereotypes against particular groups, an example being the predominantly negative evaluations of clear-l by Chinese listeners in this study, which do not reflect the true reality of use by the Malay community. 


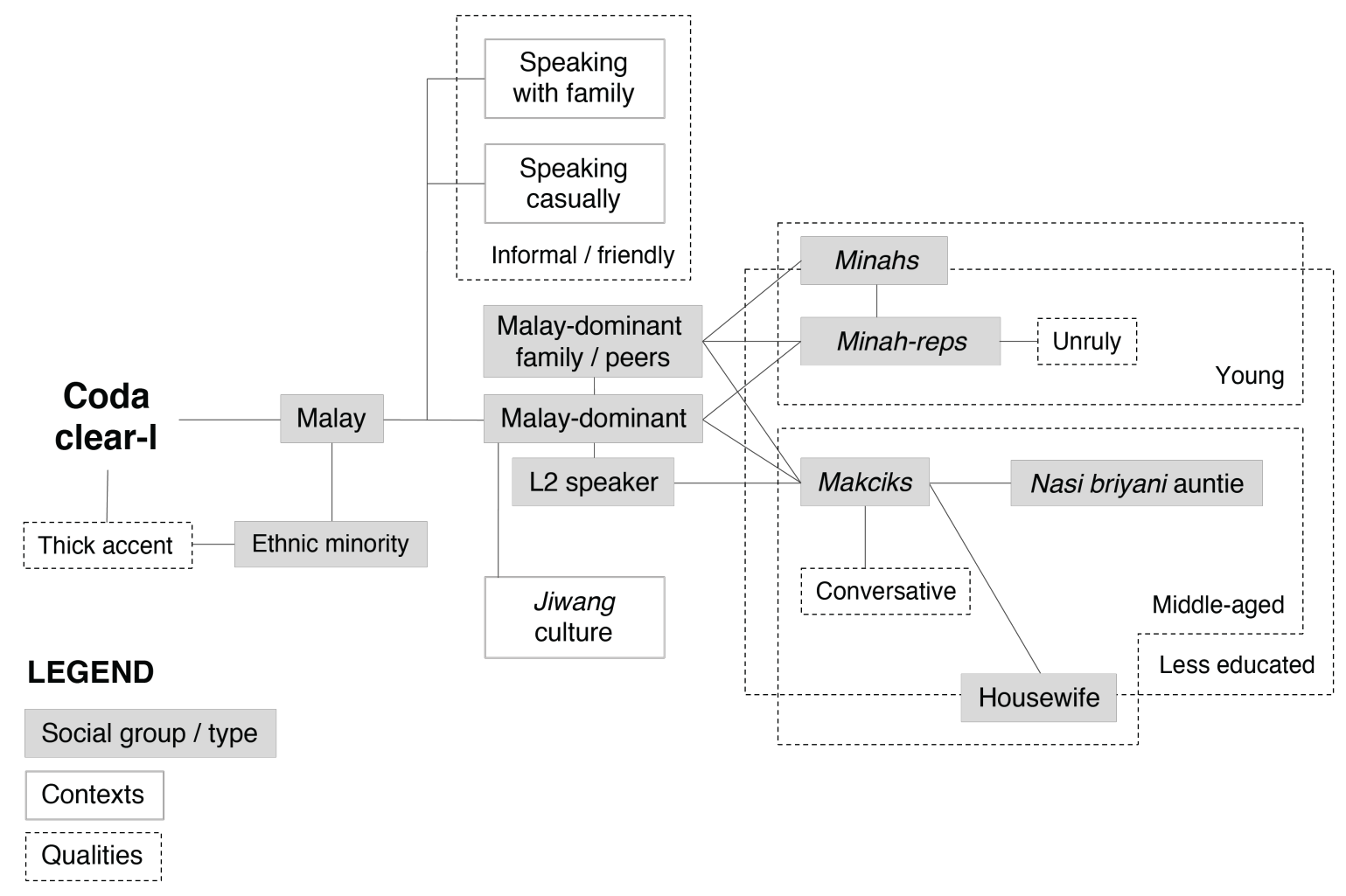

Figure 5. An example of how Malay-related social meanings of clear-l are connected

\subsection{A shared indexical field}

By expanding on Eckert's (2008a) notion of an indexical field, the meaning network of each variant of $/ 1 /$ can be further combined to form a coherent view of social meanings, as presented in Figure 6. In this approach, social meanings are relative; they can be closer to/further from, each variant. While some are more distinct to each variant, such as social types angmoh and minah, some are equally shared between two or more variants, such as 'middle-aged' and 'young'. Again, social meanings are inter-related (only a few connections are shown, for the sake of clarity). The index of 'migrant' for clear-l, for instance, is accessible through the index of 'Indian', and so are the associated qualities of formality and educatedness, which speakers who were perceived to be Malay did not evoke. By describing the relationship of social meanings in this way, and based on how indexical fields are intended to be fluid, the model can be useful in comparing how meanings are organised differently or are absent/present between groups of individuals (e.g. old versus young). It can also be useful to reflect change in a community; meanings can be constantly updated based on changes to the social world, where indices can gain or lose affinity with each variant. An example is how status traits like 'fluent', 'formal' and 'standard' might have been very far from vocalised-1 for the generation of Singaporeans who were mainly L2 speakers, but are here positioned closer to vocalised-l to reflect the diversity in present views that may point to an emerging local standard. 


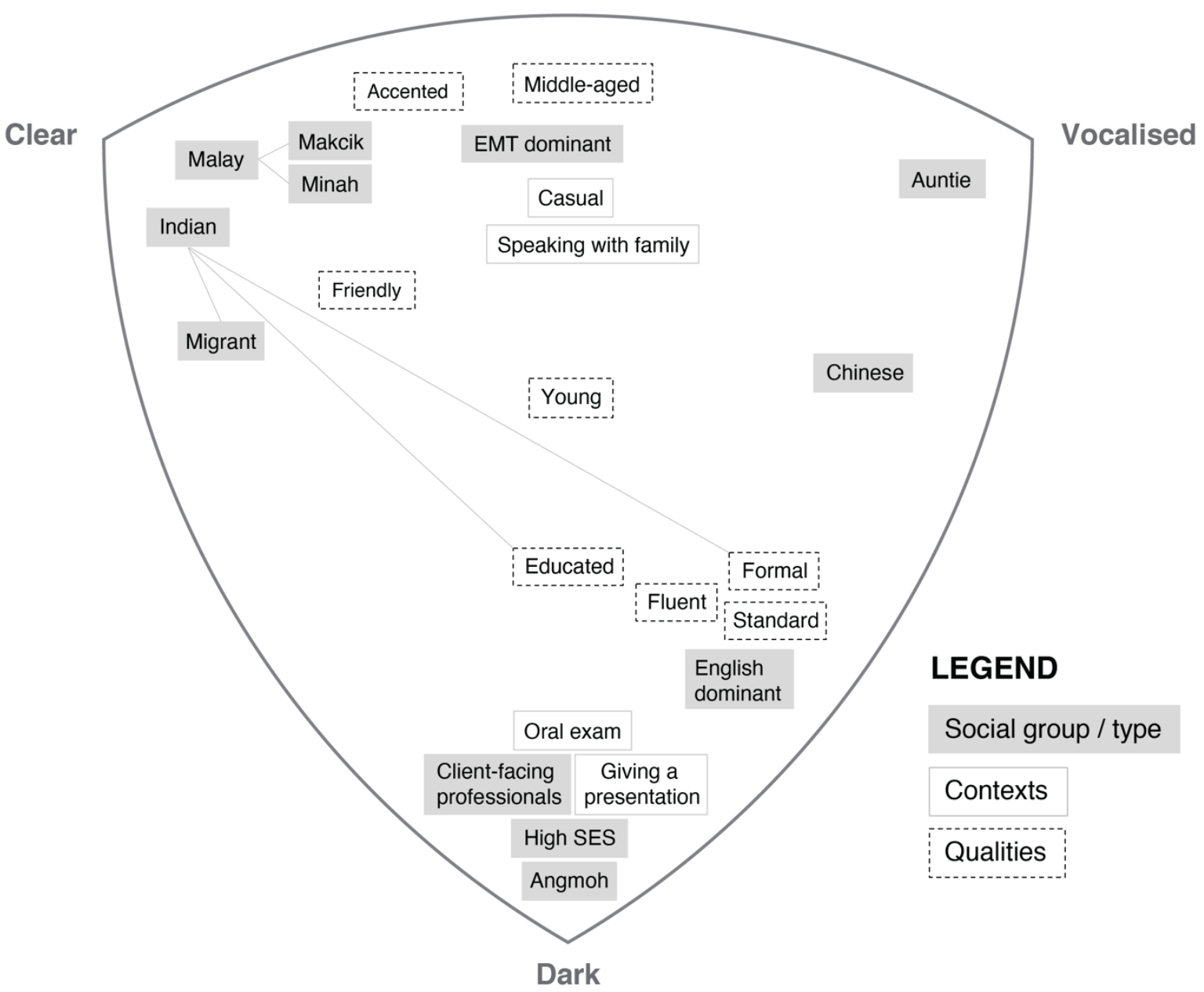

Figure 6. A shared indexical field of three variants of /// in Singapore English

\section{Conclusions}

This study has shown how differential speech features that arose from language contact and acquisition, specifically vocalised-l and clear-l, can come to index very diverse social meanings, but are connected by the social factors that have shaped them, to form an intricate network of interrelated signs that make up the fabric of a plural society. The findings also showed how the meanings associated with the variants of / / can evolve with the changing sociolinguistic landscape, in different ways, and in response to socio-political forces that regulate social perception. The resulting myriad interpretations reflect the very unique individual experiences, but also show that limited experiences with the social world may contribute to accent-based prejudice towards others in the plural society. 


\section{References}

Agha, A. (2003). The social life of cultural value. Language \& Communication, 23(3), 231-273. https://doi.org/10.1016/S0271-5309(03)00012-0

Agha, A. (2007). Language and social relations. Cambridge: Cambridge University Press. Retrieved from http://search.ebscohost.com/login.aspx?direct=true\&scope=site \&db=nlebk\&AN=178874

Alsagoff, L. (2007). Singlish: Negotiating culture, capital and identity. In V. Vaish, G. Saravanan, \& Y. Liu (Eds.), Language, Capital, Culture (pp. 25-46). Rotterdam: Sense Publishers.

Bates, D., Mächler, M., Bolker, B., \& Walker, S. (2015). Fitting Linear Mixed-Effects Models Using lme4. Journal of Statistical Software, 67(1). https://doi.org/10.18637/jss.v067.i01

Benor, S. B. (2010). Ethnolinguistic repertoire: Shifting the analytic focus in language and ethnicity. Journal of Sociolinguistics, 14(2), 159-183. https://doi.org/10.1111/j.1467-9841.2010.00440.x

Boersma, P., \& Weenink, D. (2019). Praat: Doing phonetics by computer (Version 6.0.45). Retrieved from http://www.praat.org/

Campbell-Kibler, K. (2007). Accent, (ing), and the social logic of listener perceptions. American Speech, 82(1), 32-64. https://doi.org/10.1215/00031283-2007-002

Campbell-Kibler, K. (2008). I'll be the judge of that: Diversity in social perceptions of (ING). Language in Society, 37(5), 637-659. https:// doi.org/10.1017/S0047404508080974

Campbell-Kibler, K. (2009). The nature of sociolinguistic perception. Language Variation and Change, 21(1), 135-156. https://doi.org/10.1017/S0954394509000052

Cavallaro, F., \& Chin, N. B. (2009). Between status and solidarity in Singapore. World Englishes, 28(2), 143 159. https:// doi.org/10.1111/j.1467-971X.2009.01580.x

Cavallaro, F., Ng, B. C., \& Seilhamer, M. F. (2014). Singapore Colloquial English: Issues of prestige and identity. World Englishes, 33(3), 378-397. https://doi.org/10.1111/weng.12096

Chappell, W. (2016). On the social perception of intervocalic /s/ voicing in Costa Rican Spanish. Language Variation and Change, 28(3),357-378.https://doi.org/10.1017/S0954394516000107

Christensen, R. H. B. (2019). ordinal—Regression Models for Ordinal Data (Version 2019.12-10) [R package]. Retrieved from https://CRAN.R-project.org/package $=$ ordinal.

Deterding, D. (2007a). Singapore English. Edinburgh University Press. https:// doi.org/10.3366/edinburgh/9780748625444.001.0001

Deterding, D. (2007b). The Vowels of the Different Ethnic Groups in Singapore. In D. Prescott, A. Kirkpatrick, I. Martin, \& A. Hashim (Eds.), English in Southeast Asia: Literacies, Literatures and Varieties (pp. 2-29). Newcastle, UK: Cambridge Scholars Press.

Dong, J. (2010). The enregisterment of Putonghua in practice. Language \& Communication, 30(4), 265275. https:// doi.org/10.1016/j.langcom.2010.03.001

Eckert, P. (2008a). Variation and the indexical field. Journal of Sociolinguistics, 12(4), 453-476. https:// doi.org/10.1111/j.1467-9841.2008.00374.x

Eckert, P. (2008b). Where do ethnolects stop? International Journal of Bilingualism, 12(1-2), 25-42. https://doi.org/10.1177/13670069080120010301

Eckert, P. (2012). Three Waves of Variation Study: The Emergence of Meaning in the Study of Sociolinguistic Variation. Annual Review of Anthropology, 41(1), 87-100. https:// doi.org/10.1146/annurev-anthro-092611-145828

Fridland, V., Bartlett, K., \& Kreuz, R. (2004). Do you hear what I hear? Experimental measurement of the perceptual salience of acoustically manipulated vowel variants by Southern speakers in Memphis, TN. Language Variation and Change, 16(01). https:// doi.org/10.1017/S0954394504161012

Gnevsheva, K. (2020). The role of style in the ethnolect: Style-shifting in the use of ethnolectal features in first- and second-generation speakers. International Journal of Bilingualism, 24(4), 861-880. https:// doi.org/10.1177/1367006920902520 
Graff, D., Labov, W., \& Harris, A. W. (1986). Testing listeners' reactions to phonological markers of ethnic identity: A new method for sociolinguistic research. In D. Sankoff (Ed.), Diversity and Diachrony (pp.45-58). Philadelphia: John Benhamins.

Gut, U. (2011). Studying structural innovations in New English varieties. In J. Mukherjee \& M. Hundt (Eds.), Studies in Corpus Linguistics (Vol. 44, pp. 101-124). Amsterdam: John Benjamins Publishing Company. https:// doi.org/10.1075/scl.44.06gut

Hoffman, M. F., \& Walker, J. A. (2010). Ethnolects and the city: Ethnic orientation and linguistic variation in Toronto English. Language Variation and Change, 22(1), 37-67. https://doi.org/10.1017/S0954394509990238

Johnstone, B., \& Kiesling, S. F. (2008). Indexicality and experience: Exploring the meanings of / aw/monophthongization in Pittsburgh. Journal of Sociolinguistics, 12(1), 5-33. https:// doi.org/10.1111/j.1467-9841.2008.00351.x

Khattab, G. (2002). /L/ production in English-Arabic bilingual speakers. International Journal of Bilingualism, 6(3), 335-353. https://doi.org/10.1177/13670069020060030701

Kirkham, S. (2017). Ethnicity and phonetic variation in Sheffield English liquids. Journal of the International Phonetic Association, 47(1), 17-35. https:// doi.org/10.1017/S0025100316000268

Kuznetsova, A., Brockhoff, P. B., \& Christensen, R. H. B. (2017). lmerTest Package: Tests in Linear Mixed Effects Models. Journal of Statistical Software, 82(13). https:// doi.org/10.18637/jss.v082.i13

Leimgruber, J. R. E. (2013). Singapore English: Structure, Variation, and Usage. Cambridge: Cambridge University Press. https:// doi.org/10.1017/CBO9781139225755

Lim, L. (2000). Ethnic group differences aligned? Intonation patterns of Chinese, Indian and Malay Singaporean English. In A. Brown, D. Deterding, \& E. L. Low (Eds.), The English Language in Singapore: Research on Pronunciation (pp. 10-21). Singapore Association for Applied Linguistics.

Pharao, N., Maegaard, M., Møller, J. S., \& Kristiansen, T. (2014). Indexical meanings of [s+] among Copenhagen youth: Social perception of a phonetic variant in different prosodic contexts. Language in Society, 43(1), 1-31.

Plichta, B., \& Preston, D. R. (2005). The /ay/s have It the perception of /ay/ as a north-south stereotype in United States English. Acta Linguistica Hafniensia, 37(1), 107-130. https:// doi.org/10.1080/03740463.2005.10416086

R Core Team. (2020). R: A language and environment for statistical computing. Vienna, Austria: R Foundation for Statistical Computing. Retrieved from https:/ /www.R-project.org/

Recasens, D. (2004). Darkness in [1] as a scalar phonetic property: Implications for phonology and articulatory control. Clinical Linguistics \& Phonetics, 18(6-8), 593-603. https:// doi.org/10.1080/02699200410001703556

Recasens, D. (2012). A cross-language acoustic study of initial and final allophones of /1/. Speech Communication, 54(3),368-383.https://doi.org/10.1016/j.specom.2011.10.001

Recasens, D., \& Espinosa, A. (2005). Articulatory, positional and coarticulatory characteristics for clear /1/ and dark /1/: Evidence from two Catalan dialects. Journal of the International Phonetic Association, 35(1), 1-25. https://doi.org/10.1017/S0025100305001878

Rubdy, R. (2001). Creative destruction: Singapore's Speak Good English movement. World Englishes, 20(3), 341-355.https://doi.org/10.1111/1467-971X.00219

Sailaja, P. (2009). Indian English. Edinburgh: Edinburgh Univ. Press.

Schneider, E. W. (2003). The Dynamics of New Englishes: From Identity Construction to Dialect Birth. Language, 79(2), 233-281.

Schneider, E. W. (2012). English as a contact language: The "New Englishes." In D. Schreier \& M. Hundt (Eds.), English as a Contact Language (pp. 131-148). Cambridge: Cambridge University Press. https://doi.org/10.1017/CBO9780511740060.008 
Sharma, D. (2011). Style repertoire and social change in British Asian English. Journal of Sociolinguistics, 15(4), 464-492.https://doi.org/10.1111/j.1467-9841.2011.00503.x

Sharma, D., \& Sankaran, L. (2011). Cognitive and social forces in dialect shift: Gradual change in London Asian speech. Language Variation and Change, 23(3), 399-428. https://doi.org/10.1017/S0954394511000159

Silverstein, M. (2003). Indexical order and the dialectics of sociolinguistic life. Language \& Communication, 23(3), 193-229. https://doi.org/10.1016/S0271-5309(03)00013-2

Sim, J. H. (2019). "But you don't sound Malay!": Language dominance and variation in the accents of EnglishMalay bilinguals in Singapore. English World-Wide, 40(1), 79-108. https://doi.org/10.1075/eww.00023.sim

Simonet, M. (2010a). Alveolar laterals in Majorcan Spanish: Effects of contact with Catalan? In S. Colina, A. Olarrea, \& A. M. Carvalho (Eds.), Current Issues in Linguistic Theory (Vol. 315, pp. 81-94). Amsterdam: John Benjamins Publishing Company. https://doi.org/10.1075/cilt.315.05sim

Simonet, M. (2010b). Dark and clear laterals in Catalan and Spanish: Interaction of phonetic categories in early bilinguals. Journal of Phonetics, 38(4), 663-678. https://doi.org/10.1016/j.wocn.2010.10.002

Tan, K. K. (2005). Vocalisation of /l/ in Singapore English. In D. Deterding, A. Brown, \& E. L. Low (Eds.), English in Singapore: Phonetic Research on a Corpus. McGraw Hill.

Walker, A., García, C., Cortés, Y., \& Campbell-Kibler, K. (2014). Comparing social meanings across listener and speaker groups: The indexical field of Spanish /s/. Language Variation and Change, 26(2), 169 189. https:// doi.org/10.1017/S0954394514000088

Wells, J. C. (1992). The British Isles (Reprinted). Cambridge: Cambridge University Press.

Wong, J. (2006). Contextualizing aunty in Singaporean English. World Englishes, 25(3-4), 451-466. https:// doi.org/10.1111/j.1467-971X.2006.00481.x

Woods, K. J. P., Siegel, M. H., Traer, J., \& McDermott, J. H. (2017). Headphone screening to facilitate webbased auditory experiments. Attention, Perception, \& Psychophysics, 79(7), 2064-2072. https:// doi.org/10.3758/s13414-017-1361-2 